$33.75,51.25$ h). Prior to the haemorrhage all had significantly improved pulmonary function (ventilation pressures and oxygenation); three extubated. 6 had evidence of PDA, 3 had widened pulse pressure, 3 had systolic murmurs or echocardiographic evidence of PDA. After the haemorrhage all babies deteriorated with X-ray changes. One baby died. All 9 survivors developed clinically significant PDA requiring treatment. (1 duct ligation, 8 managed medically).

Conclusions All affected babies had a combination of risk factors for pulmonary haemorrhage. In addition they all exhibited a rapid improvement in ventilatory requirements lending weight to the the theory that falling pulmonary vascular resistance with increased pulmonary blood flow is a causative factor.

\section{PO-0751 USE OF POSTNATAL STEROIDS IN VENTILATOR DEPENDANT PRETERM INFANTS}

${ }^{1} \mathrm{~N}$ Merchant, ${ }^{2} \mathrm{~A}$ Zovidavi, ${ }^{1} \mathrm{H}$ Cullen, ${ }^{2} \mathrm{~A}$ Huertas-Ceballos, ${ }^{2} \mathrm{~S}$ Watkin. ${ }^{1}$ Centre for the Developing Brain Perinatal Imaging and Health, King's College London, London, UK; ${ }^{2}$ Neonatology, University College London Hospital, London, UK

\subsection{6/archdischild-2014-307384.1390}

Background and aim Bronchopulmonary Dysplasia (BPD), results in prolonged hospitalisation, poor growth and adverseneurodevelopment outcome. Postnatal steroids may decrease prolonged ventilation, one of the risk factors for BPD. However, there are concerns about adverse effects of steroids.

The aim of the study was to assess the safety and efficacy of hydrocortisonein ventilator dependant preterm infants, thus ensuring safe practice and improve the quality of care given.

Methods The study was a retrospective analysis over 17 months (Jan 2012-May 2013) in preterm infants less than 32 weeks gestation. Demographic data along with data on adverse effects related to hydrocortisone was collected.

Results Fifteen percent (42/281) of preterm infants received hydrocortisone starting at dose of $5 \mathrm{mg} / \mathrm{kg} / \mathrm{d}$ to aid extubation. The mean gestation was 25.17 weeks with a mean birth weight of 696 g. Forty-six percent had more than one failed extubation, $54 \%$ required $>90 \%$ oxygen pre-treatment and $70 \%$ had either medical or surgical intervention for PDA. Only 24\% had a documented discussion with parents regarding steroid treatment. The dose was reduced by $0.5-1 \mathrm{mg} / \mathrm{kg}$, the time frequency of reduction varied between 1-7 days.

Adverse events related to hydrocortisone treatment included hypertension, oesophageal perforation, hyponatremic, hyperglycaemic requiring insulin, left ventricular hypertrophy, fractures and poor weight gain.

Conclusions The incidence of steroid use reflected that of other centres. Awareness of adverse events related to use of steroids along with improved parental communication is required.

\section{P0-0752 INCIDENCE AND CLINICAL IMPACT OF RESPIRATORY DISEASE IN PREMATURE INFANTS WITH LOW BIRTH WEIGHT}

M Muñoz-Garcia, C Santiago-Gutiérrez, MC Martínez-Padilla, M Cubero-Sánchez, J de la Cruz-Moreno. Department of Pediatrics, Complejo Hospitalario de Jaén, Jaén, Spain

\subsection{6/archdischild-2014-307384.1391}

Advances in perinatal care have made it possible to improve survival of infants with low birth weight. The aim of study was to analyse the clinical impact of respiratory disease in premature infants with low birth weight. Methods: Between January-2011 and November-2012 were included 81 preterm infants with low birth weight and $\leq 32$ weeks gestation. Data are expressed in according to birth weight defined as: extremely low $<1000 \mathrm{~g}$ (ELBW), very low 1001-1500 g (VLBW) and low weight 15012000 g (LBW). Results: $84.8 \%$ of preterm infants received respiratory support by CPAP and in 46 cases $(56.8 \%)$ was explained by mechanical ventilation. Endotracheal surfactant was administered in 34 infants $(42 \%)$. Only 3 preterm did not require oxygen. $86.4 \%$ of infants with less than 28 weeks required mechanical ventilation compared to $45.8 \%$ of infants $>28$ weeks gestation. The incidence of morbidities such as bronchopulmonary dysplasia, pulmonary haemorrhage and pneumothorax was very low: $6.2 \%, 4.9 \%$ and $1.25 \%$, respectively. The mean number of days requiring mechanical ventilation and treatment with caffeine for apnea was higher for ELBW compared to VLBW and $\mathrm{LBW}(6.7 \pm 5.5$ vs. $4.1 \pm 4.7$ vs. $3.38 \pm 2.7, \mathrm{p}=0.023$ and $38.1 \pm 7.3$ vs. $26.8 \pm 15$ vs. $12 \pm 7.8, \mathrm{p}=0.01$, respectively). The onset of bronchopulmonary dysplasia occurred in 5 preterm with ELBW. In all preterm infants who died required mechanical ventilation vs. who those survived 14 (100\%) vs. 32 $(47.8 \%), \mathrm{p}=0.001$ and greater need of surfactant $10(71.4 \%)$ vs. $24(35.8 \%), p=0.047$. Conclusions: Although the most preterm with low birth weight require respiratory support, the incidence of complications in our series is low.

\section{P0-0753 VIDEOLARYNGOSCOPY AS AN INTUBATION TRAINING TOOL FOR NEONATAL TRAINEES - A RANDOMISED CONTROLLED TRIAL}

JE O'Shea, M Thio, COF Kamlin, L McGrory, J John, C Robets, C Kuschel, PG Davis. Department of Newborn Research, Royal Women's Hospital, Melbourne, Australia

\subsection{6/archdischild-2014-307384.1392}

Background and aims Endotracheal intubation is a mandatory skill for neonatal trainees. However, it is difficult to learn and junior trainees have success rates $<50 \%$. Videolaryngoscopy allows the instructor to share the same view of the pharynx as the trainee. We compared intubations guided by an instructor watching a videolaryngoscope screen with the traditional method where the instructor does not have this view.

Methods An unblinded randomised, controlled trial (ANZCTR number 12613000159752) at a tertiary neonatal centre commenced March 2013. Eligible intubations were those performed on infants in the delivery room or in the neonatal intensive care unit, by trainees with less than six months of tertiary neonatal experience. Nasal intubations, intubations in infants with facial, oral or airway abnormalities and intubations carried out by more experienced doctors were excluded. Intubations were randomised to the videolaryngoscope screen being visible or covered (control). A sample size of 206 had an $80 \%$ power to demonstrate an absolute difference of $20 \%$ in the success rate between intervention and control groups. Primary outcome was first attempt intubation success rate confirmed by colorimetric detection of expired carbon dioxide.

Results 190 intubations have been randomised since March 2013 (80\% of all eligible intubations since trial commencement). Median weight at intubation of recruited infants was $1195 \mathrm{~g}$ (range 504-4804 g), median corrected gestation 29 weeks post menstrual age (range 24-41). Recruitment will be complete by May 2014 and data analysis by July 2014.

Conclusions To follow upon completion of the trial. 